Bulletin d'Histoire Contemporaine de

I'Espagne

$50 \mid 2016$

Les intellectuels en Espagne, de la dictature à la démocratie (1939-1986)

\title{
Luis Arana e i veterani di Euzkeldun Batzokija: la corrente ortodossa del nazionalismo basco
}

Marco Perez

\section{(2) OpenEdition \\ Journals}

Edición electrónica

URL: http://journals.openedition.org/bhce/903

DOI: $10.4000 /$ bhce. 903

ISSN: 1968-3723

\section{Editor}

Presses Universitaires de Provence

Edición impresa

Fecha de publicación: 1 diciembre 2016

Paginación: 259-265

ISSN: 0987-4135

\section{Referencia electrónica}

Marco Perez, "Luis Arana e i veterani di Euzkeldun Batzokija: la corrente ortodossa del nazionalismo basco », Bulletin d'Histoire Contemporaine de l'Espagne [En línea], 50 | 2016, Publicado el 09 octubre 2018, consultado el 23 septiembre 2020. URL : http://journals.openedition.org/bhce/903 ; DOI : https://doi.org/10.4000/bhce.903 


\section{Luis Arana e i veterani di Euzkeldun Batzokija: la corrente ortodossa del nazionalismo basco ${ }^{1}$}

\section{Marco PEREZ}

En el nacionalismo vasco pocos personajes han tenido la influencia de Luis Arana, quien fue inspirador $y$, junto con su hermano Sabino, fundador del PNV. No obstante, en el plano bibliográfico y político la figura de Luis no disfrutó del éxito de Sabino, que logró ser mártir y referencia de todas las corrientes nacionalistas. Esto se debe a que Sabino Arana fue un buen intérprete de la novedad «nacionalista», por lo menos desde 1898, cuando aceptó en el interior del movimiento a algunos importantes representantes de la burguesía industrial bilbaína (reunidos alrededor de la revista Euskalduna y del empresario naval Ramón de la Sota). Si el nacionalismo vasco aspiraba a crear una alternativa al Estado-nación español (ya entendido como un problema por toda una generación de intelectuales) no podía no aceptar el reto de la modernidad. En efecto, existe una estrecha relación entre la elección sabiniana de 1898 y el repentino crecimiento del movimiento, condicionado también por el giro

1 Tesis doctoral leida el 11 de junio de 2012 en el Departamento de Política, Instituciones, Historia, de la Universidad de Bologna. Director: Prof. Alfonso Botti (U. de Modena y Reggio Emilia). Tribunal: Profs. Ferdinando Fasce (U. de Génova), Mario Del Pero (U. de Bologna), Simona Colarizi (U. «La Sapienza», Roma) y Marco Cipolloni (U. de Modena y Reggio Emilia). «industrialista» del nacionalismo (cuando Sabino decidió superar la anterior postura ruralista) y por la propuesta «españolista». En particular, el experimento españolista ha sido valorado por una copiosa bibliografia, por parte de los nacionalistas vascos (a menudo para justificar la hipótesis autonomista) y claramente en las investigaciones históricas sobre los primeros años del movimiento sabiniano, tratando de averiguar si la hipótesis planteada por Sabino Arana fue sincera o más bien una mera estrategia oportunista.

Incluso en este tema, en el primer capítulo de la tesis, se profundizará en el estado de los estudios, sobre todo en el tratamiento parcialmente autorreferencial de la «cuestión vasca». Fueron pocos los investigadores que escaparon al paradigma "constructivista», que reconoce en el nacionalismo sólo una original consecuencia del desarrollo capitalista. En el caso español, la tesis que veía en el nacionalismo vasco sólo un fenómeno "artificial» tuvo un gran éxito, a raíz de la célebre obra de Eric Hobsbawm, The Invention of Tradition (1983), o de la anterior reflexión de Caro Baroja ${ }^{2}$. En algunos casos, el nacionalismo euskaldun fue considerado irracional, por ser alternativo a un proceso de nation-builduing ya iniciado por el Estado español (mayormente legitimado bajo un perfil histórico). Los estudios más recientes han rechazado, sin embargo, el esquematismo de esta

2 E. Hobsbawm y T. Ranger (eds.), The Invention of Tradition, Cambridge, Cambridge University Press, 1983; J. Caro Baroja, El mito del carácter nacional, Madrid, Caro Raggio, 2004 (1" ed. 1970). 
interpretación, enseñando como en la formación identitaria contribuyen más elementos, relacionados con la administración racional del territorio, con las leyendas ancestrales sobre los orígenes de un pueblo (a menudo representadas por símbolos específicos o celebraciones identitarias) y también en la formación de una cultura y de una literatura nacional. La doble identidad vasca del siglo XIX ha sido adecuadamente tratada por una serie de estudios de Coro Rubio Pobes, que limitan la llamada «diferencia» vasca y la misma invención aranista ${ }^{3}$. El movimiento sabiniano, no obstante, no reflejó sólo la cultura tradicionalista española, ofreciendo, según una línea de investigación promovida por Alfonso Botti, una interpretación original y regional del nacionalcatolicismo español ${ }^{4}$.

La identidad vasca del siglo XIX se compuso de instancias carlistas, un fundamentalismo religioso típicamente vasco (conectado al modelo jesuita y a los Fueros), una identidad literaria (capaz de construir un imaginario rural), un mundo campesino aislado en el plano lingüístico y una identidad localista intravasca construida sobre las anteriores instituciones forales. El padre de los hermanos Arana, Santiago de Arana y Ansotegui, representa en su biografia la heterogénea identidad vasca del siglo XIX: miembro de la antigua burocracia foral (despojada de su tradicional función administrativa por las leyes de 1839 y 1876), armador naval y representante de la nueva burguesía bilbaína y al mismo tiempo defensor entusiasta de los derechos de la República de Abando (la antigua anteiglesia foral adyacente a Bilbao).

3 C. Rubio PoBes, La identidad vasca en el siglo XIX: discursos $y$ agentes sociales, Madrid, Biblioteca Nueva, 2003.

4 A. Boтt, Cielo y dinero: el nacionalcatolicismo en España (1881-1975), Madrid, Alianza Editorial, $2008\left(1^{\mathrm{a}} \mathrm{ed}\right.$. española 1992, $1^{\mathrm{a}} \mathrm{ed}$. italiana 1992).
Luis Arana, relatando un episodio de su infancia, recordó la indignación de su padre hacia los proyectos anexionistas de Bilbao. Para Santiago Arana, las anteiglesias eran políticamente superiores a las ciudades, porque eran más antiguas y porque su territorio pertenecía a las familias vascas «originarias». Este enfoque fue estrictamente adoptado por Luis Arana. No por casualidad Luis se opuso a los giros repentinos de su hermano, considerando un error la alianza con Euskalduna y con personajes ajenos a la primitiva experiencia de Euzkeldun Batzokija. En este sentido, el segundo capítulo tratará de arrojar luz sobre la formación de Luis Arana, mostrando la influencia ejercida por la literatura foral y por las leyendas sobre los orígenes ancestrales de los vascos. Los estudios (realizados en colegios dirigidos por jesuitas) fomentaron el enfoque vasquista de su fuerismo, gravitando en la figura de Ignacio de Loyola (entendido como santo vasco por antonomasia). La ortodoxia jesuita fue además asociada con la raza vasca en un plano biológico, por su «limpieza de sangre» (por el hecho de no haberse mezclado con pueblos paganos enemigos del cristianismo).

Si el nacionalismo vasco fue el ejemplo más visible de socialización política del pueblo euskaldun, gozando en esto de la rápida industrialización bilbaína, su imaginario histórico-literario se definió a partir del Siglo de Oro español (por los antiguos cronistas vascos y como principal soporte ideológico de los Fueros). Las leyendas vasco-cantábricas y vascoibéricas se referían a la libertad histórica del País Vasco (que supuestamente no había sufrido la dominación romana, visigoda y árabe), la nobleza y la igualdad universal de Vizcaya (que hacía de todo vizcaíno un noble de nacimiento) y el monoteísmo ancestral del pueblo vasco (teóricamente descendiente directo de 
Túbal, nieto de Noé). Estas leyendas ayudaron a justificar la existencia de una serie de privilegios fiscales y territoriales, y la existencia misma del euskera (supuestamente importado por Túbal). La mitología vasca, hábilmente aprovechada por los jesuitas locales, creó ese elemento diferencial, en términos de identidad, que posteriormente hizo posible el éxito del nacionalismo. En este sentido, la nobleza universal de los vascos fue el resultado de su pureza racial (siendo la única población ibérica que no se había mezclado con elementos semíticos). La lengua vasca era la lengua de la ortodoxia, porque carecía de expresiones blasfemas; mientras el ancestral origen tubálico hacía de los vascos uno de los pueblos de origen bíblico.

Ceferino de Jemein, historiador y político del nacionalismo ortodoxo, minimizará la influencia que la literatura foral tuvo en el pensamiento sabiniano, influencia que fue rechazada por los historiadores de la izquierda abertzale (poco interesados en valorar los orígenes mítico-religiosos de la identidad vasca) y por la bibliografía postfranquista (porque era ajena al paradigma "constructivista» del nacionalismo).

Luis Arana resultó, sin embargo, muy condicionado por esta producción (tanto por la literatura legendaria del Siglo de Oro como por la bucólica y rural, de inspiración fuerista). Los escritos del siglo XVIII del jesuita vasco Manuel Larramendi muestran la propagación de esas mitologías en la Orden fundada por Ignacio de Loyola. En este sentido, Luis Arana colocó el nacimiento del nacionalismo en el interior de la institución jesuita, y precisamente durante el curso académico 1879-1880 (dos años antes de la conversión de Sabino). Como hermano mayor de Sabino, él siempre rehusó su sacralización, aun reconociendo su función del líder. La definición del «primitivo nacionalismo vasco», por él pensado a la par de un dogma religioso, se refirió a la primera fase de la reflexión sabiniana (la más radical). Como líder de la corriente ortodoxa promovió una interpretación original de los Fueros (que atribuyó en un segundo momento a Sabino). El primer núcleo del movimiento fue constituido por el círculo de Euzkeldun Batzokija, fundado en 1894 y cuyo estatuto fue presentado por Luis Arana como la esencia misma del nacionalismo primitivo, en contraste con la corriente liberal de Euskalduna, pero incluso con respecto al trabajo del último Sabino. Para Luis Arana los Fueros no representaron la bandera sobre la que construir un moderno movimiento de masas, sino la única institución posible para el pueblo vasco (ya que se basaba en las características morales y raciales de la población euskaldun).

Como su padre Santiago, y de acuerdo con una postura identitaria ya presente en el siglo XVIII, también Luis creía en una sociedad teocrática, basada en los principios y en la ortodoxia en su momento definida por Ignacio de Loyola. Los Fueros promovían, para Luis, la naturaleza libre y confederal de los vizcaínos, representados desde la familia (como base de la sociedad cristiana y vasca) hasta la república confederal de Euskadi. En orden de importancia, después de la familia se encontraba la anteiglesia (entendida como una república autónoma) y a continuación los valles y las ciudades. Todas las entidades políticas vascas poseían un derecho de secesión, formando una confederación basada en el consenso y en el «individualismo vasco». Un concepto que no debe confundirse (a pesar de que así fue entendido por los enemigos de Luis Arana) con el individualismo liberal, decretando simplemente la sumisión de la política (y de los gobiernos) a la autoridad católica, cuya presencia se percibía especialmente en las anteiglesias. La tesis relativa al individualismo vasco se mostró en una serie de artículos y con más fuerza en la Historia de Bizkaya (1910) de Ángel 
Zabala, lider del PNV durante la transición post-sabiniana. De hecho Ángel Zabala fue el principal exponente, después de Luis Arana, de la primera generación de aranistas ortodoxos, que también incluyó a Ciriaco de Llodio, Fabián de Ispizua y Miguel Cortés. La corriente ortodoxa se componía primariamente por los fundadores del primer círculo nacionalista: Euzkeldun Batzokija (EB). A ellos competía preservar, en las intenciones de Luis Arana, la ortodoxia del primitivo nacionalismo, de acuerdo con la dirección establecida por los estatutos de EB. Por la misma razón, los militantes cercanos a la revista Euskalduna criticaron la actitud sectaria de los veteranos, definiendo irónicamente al grupo de Luis Arana la «guardia negra» de Sabino.

Esta vocación sacerdotal en la gestión del partido y de su teoría, acompañó constantemente la acción política de Luis Arana. En un plano cronológico la biografia política de Luis se puede dividir en siete etapas básicas: en la fundación del movimiento y del nacionalismo originario (1880-1898); como consejero de Sabino y guardián de la ortodoxia (1898-1908); como guía y líder del PNV (1908-1915); en la dirección del partido ortodoxo de Euzkeldun Batzokija (1916-1922) y del nuevo PNV aberriniano (1922-1930); como promotor de la temporal «vuelta a Sabino» (19301933) y finalmente como oponente de las políticas reformistas del PNV (1933-1951). Más que por el contraste entre autonomistas y separatistas, la dialéctica del movimiento vio como protagonistas a los ortodoxos del nacionalismo primitivo (con referencia a la inicial postura sabiniana) y, en el lado opuesto, el heterogéneo frente reformista (considerando los enfoques liberales, democristianos y socialistas que se asomaron progresivamente en el PNV). Esta dialéctica era funcional al dualismo rígido de Luis Arana, quien veía la causa vasca principalmente en un plano religioso $\mathrm{y}$, por tanto, en constante lucha contra el pecado (representado por el socialismo y el liberalismo) y la herejía (representada por el nacionalismo heterodoxo). Para Luis Arana, el nacionalismo y la misma identidad vasca se basaban en los principios del catolicismo romano. La misma autonomía política de Euskadi era motivada por razones religiosas, permitiendo a la raza vasca (presumiblemente distinguida por su ortodoxia católica) romper los lazos con la latina (falsamente católica, degenerada y racialmente impura). En este sentido se rechazó la proyectada alianza con los nacionalismos gallego y catalán, reconociendo en ellos un "voluntarismo» lingüístico y cultural ajeno a las razones etno-religiosas del movimiento euskaldun. El enfoque político de Luis Arana no traicionaba su sometimiento al catolicismo más tradicional, haciendo de hecho poco probable aquella transferencia de lo sagrado (en el ámbito de una religión política nacionalista) que el historiador Antonio Elorza atribuyó al aranismo ${ }^{5}$.

El tercer y cuarto capítulos están centrados en la primera década del siglo XX, profundizando en la etapa reformista inaugurada por Sabino y la transición post-sabiniana gestionada por la corriente ortodoxa. Como Luis Arana tuvo ocasión de recordar a su amigo Zabala, cuando éste se hizo cargo de la dirección del partido, el PNV tenía que inspirarse en los principios autoritarios y religiosos de la Orden jesuita y en el enfoque confederal previsto por los Fueros. En la definición de la micro-política del PNV se ha hecho un amplio uso de la prensa nacionalista, tanto de la oficial (los órganos editoriales del partido) como de la relacionada con corrientes específicas del movimiento. En este sentido, he tratado de esquematizar la evolución teórica del

5 A. Elorza, Tras la huella de Sabino Arana: los orígenes totalitarios del nacionalismo vasco, Madrid, Temas de Hoy, 2005, y «Los integrismos», Madrid, Historia 16, 1995. 
PNV según las líneas dictadas por su prensa y concretamente con respecto a la cuestión de las nacionalidades europeas. La corriente ortodoxa de Luis Arana mantuvo sobre tal asunto posiciones decididamente autorreferenciales, reacias a comparar la causa nacional vasca (que pretendía salvar la religiosidad tradicional de Euskadi) con el más internacional resurgimiento de las nacionalidades (incluidas las sujetas al poder colonial).

Luis Arana, quien en 1908 había recuperado la dirección del partido a la ortodoxia, tuvo ocasión de enfrentarse en la «cuestión de las nacionalidades» con Engracio Aranzadi, que fue líder del nacionalismo guipuzcoano (además de ser uno de los primeros colaboradores de los hermanos Arana). La relación entre los dos fue siempre acompañada de una cierta tensión, por la posición pragmática y de mediación mantenida por el líder guipuzcoano. Cuando Aranzadi asumió en 1913 la dirección del diario nacionalista Euzkadi, promovió una renovación teórica y generacional del movimiento euskaldun. Se apoyaron causas nacionales ajenas al catolicismo, añadiendo a la lucha irlandesa o polaca las de países exóticos y extraeuropeos. Sobre esta cuestión, el quinto capítulo muestra cómo en el ocaso de la presidencia de Luis Arana (1908-1915) se produjo la progresiva desunión de muchos de los altos directivos (sensibles a una renovación pragmática del aranismo). Unos años antes el partido había experimentado una dramática confrontación con el obispo de Vitoria Cadena y Eleta, cuya razón principal residía en la aversión nacionalista a integrarse en los bloques electorales católicos. Este enfrentamiento hizo explícito el límite estratégico del aranismo y del confesionalismo nacionalista, que no consiguió representar de forma homogénea los intereses de los católicos vascos (en función antiespañolista y anti-socialista). En este sentido el nacionalcatolicismo aranista (que fusionaba la identidad vasca con la católica) chocó con el español, que contó con el sustancial apoyo de las jerarquías vaticanas. Luis Arana insistía, por otro lado, en la razón católica del nacionalismo primitivo, reconstruyendo el círculo de los veteranos nacionalistas de Euzkeldun Batzokija (sobre el modelo de la Orden fundada por Ignacio de Loyola) como garantía de la ortodoxia sabiniana.

El liderazgo político de Luis Arana, sin embargo, se hizo más débil por su vocación sectaria y abiertamente cuestionada por Engracio Aranzadi, públicamente anglófilo en la política exterior y favorable a la hipótesis autonomista. La expulsión de Luis Arana en 1915 causó la escisión de la parte más ortodoxa del partido (ahora reunida en torno a Euzkeldun Batzokija y al semanario Bizkaitarra). El dirigente bilbaíno estaba, sin embargo, lejos de ser derrotado y comenzó una cruzada contra lo que llamó «traidores» del nacionalismo primitivo, ironizando sobre los entusiasmos wilsonianos que habían contagiado a Engracio Aranzadi y a la dirección de la Comunión Nacionalista Vasca. Será tarea del sexto capítulo describir la reorganización de la corriente ortodoxa como corriente de oposición. Luis Arana, siempre a la cabeza de los viejos veteranos nacionalistas, decidió unirse a los jóvenes nacionalistas del semanario Aberri y con ellos traspasar la larga noche representada por la dictadura de Primo de Rivera. Con gran consternación del anciano líder, en el mundo nacionalista habían surgido más formas de entender la causa vasca (algunas de las cuales eran abiertamente aconfesionales). Al principio de los años treinta, podemos reconocer un grupo centrista y pragmático (en torno a Engracio Aranzadi), una izquierda social representada por Elías Gallastegui (figura clave del semanario Aberri) y un sector 
sensible a la renovación democrática del mundo católico. La reunificación del partido (que tuvo lugar en Vergara en noviembre de 1930) fue precedida por un extenso debate teórico, que favoreció al sector ortodoxo. Luis Arana fue capaz, de hecho, de atraer a un cierto número de jóvenes, que reemplazaron gradualmente a los viejos veteranos del nacionalismo primitivo. La escisión del sector liberal de izquierda (que no quiso aceptar el enfoque todavía estrictamente confesional del partido) favoreció aún más a los ortodoxos aranistas. El proyecto estatutario de 1931 (entendido por las fuerzas de izquierda como el intento de crear un «Gibraltar vaticanista» en el cuerpo mismo de la República), acompañó la última ilusión del sector ortodoxo, en la creación de un frente único católico liderado por los nacionalistas.

Entre los dirigentes que Luis Arana fue capaz de atraer a la corriente ortodoxa deben ser mencionados Ceferino de Jemein y Manuel Eguileor, quienes fueron los principales protagonistas del proceso de santificación del anciano líder bilbaíno (ahora convertido en el protagonista de la fiesta colectiva más importante del nacionalismo, el Aberri Eguna). Fue un momento emocionante para Luis Arana, quien en el mismo año recuperó el liderazgo del partido y fue capaz de publicar un pequeño formulario de los principios del nacionalismo primitivo (con la esperanza de difundir y consolidar la ortodoxia sabiniana) ${ }^{6}$.

Unos meses más tarde, sin embargo, salió el folleto anónimo Nacionalismo-JudaísmoComunismo, que resumía la nueva línea propagandista de las derechas españolas?.

6 L. Arana-Goiri, Formulario de los principios esenciales o básicos del primitivo nacionalismo vasco contenidos en el lema Jaun-Goikua eta Lagi-Zarra, Abando-Bilbao, Grijelmo, 1932.

7 Judaismo-Nacionalismo-Comunismo, en el Archivo del Nacionalismo, Pnv_Nac_Ebb, K. 316 , C. 5 .
Al igual que en 1910, durante el arzobispado de Cadena y Eleta, el PNV fue acusado de favorecer implícitamente a las izquierdas en la formación de un frente unido «rojoseparatista». El nacionalcatolicismo aranista volvió a mostrar sus límites estratégicos, en un momento de fuerte radicalización de la política española. La Asamblea nacionalista que se celebró en Tolosa en enero de 1933 trató de poner remedio a esta situación, haciendo emerger una nueva generación de dirigentes (de la talla de José Antonio Aguirre y Manuel Irujo) dispuestos a aceptar compromisos con las instituciones republicanas $y$ disponibles a contaminarse en sentido demócrata-cristiano.

Luis Arana pareció entender con retraso la magnitud del giro reformista, valorando con optimismo la fuerza de los principios sabinianos y su difusión en el partido. La alianza con los nacionalismos gallego y catalán y la elección de apoyar a la República en la guerra civil causaron, sin embargo, su baja del partido. Estas opciones, para Luis Arana, contradecían e insultaban los fines religiosos del nacionalismo. El último capítulo muestra cómo Luis Arana pasó los últimos años de su dilatada vida luchando contra las que reconocía como degeneraciones del nacionalismo vasco. Los aranistas ortodoxos, a partir de Ceferino de Jemein y Manuel Eguileor, se transformaron gradualmente de guardianes de la ortodoxia a guardianes de la memoria. Durante los años treinta, con la excepción del texto de Aranzadi Ereintza (1935), la reflexión histórica había estado, de hecho, monopolizada por el sector ortodoxo, que en 1932 fue capaz de publicar una primera antología del pensamiento sabiniano (titulada De su alma y de su pluma), seguida por la primera biografía de Sabino Arana en 1935, obra de Ceferino de Jemein ${ }^{8}$.

8 S. Arana Goiri, De su alma y de su pluma, Bilbao, E. Verdes Achirica, 1932; E. DE 
Jemein reemplazó a Luis Arana en su papel de guardián de la ortodoxia, recordando los principios del nacionalismo y el significado original de estos en el simbolismo del Aberri Eguna. Si el intento de santificar la figura de Luis Arana y la epopeya de la corriente aranista del PNV no tuvo el éxito esperado, Jemein consiguió de todas formas monopolizar la investigación histórica del partido, apropiándose de la tarea de publicar la primera edición completa de la obra sabiniana y fundando en 1950 el Sabindiar Batza (el Instituto de estudios sabinianos). Jemein jugó un papel clave en la recolección y preservación del patrimonio documental del archivo nacionalista, utilizándolo políticamente en contra del liderazgo del eje Aguirre-Irujo. A través de Jemein (y como último legado político de Luis Arana) se creará en el PNV la dicotómica presencia de una memoria aranista, dentro de un partido más anclado en valores europeístas y católico-democráticos.

Luis Arana no disfrutó de la misma suerte, siendo de forma gradual olvidado o relegado a un segundo plano. Manuel Irujo, en una entrevista concedida en 1977, lo considerará un personaje secundario, criticando su mediocridad y su falta de carisma. El reciente trabajo biográfico de Jean-Claude Larronde, Luis Arana, 18621951: historia del nacionalismo vasco, devuelve al personaje a la centralidad debida, proponiendo, sin embargo, una revisión no ajena de finalidades hagiográficas ${ }^{9}$.

Entre los objetivos propuestos por la tesis está la definición de la ideología aranista ortodoxa, a partir de las diferencias entre
Sabino y Luis Arana en la gestión de la modernidad y de la estrategia política. En el curso de su larga militancia, que va de 1879 (en el clima posbélico de la última guerra carlista) a 1951 (pasando por una guerra civil y dos guerras mundiales), Luis Arana fue el verdadero protagonista de la corriente ortodoxa. Sin desmerecer el papel teórico y simbólico jugado por Sabino, podemos admitir que Luis, además de ser el inspirador, fue también el "censor» de la obra de su hermano. Cuando Sabino murió en 1903, con tan solo 38 años, Luis se convirtió en el guardián de la ortodoxia, seleccionando de hecho la obra sabiniana que consideraba más en línea con su propio enfoque político. Si el PNV, partido constantemente dividido entre ortodoxos y reformistas, eligió en un momento histórico dado el camino tradicionalista, lo hizo principalmente a través de la obra de Luis Arana, personaje al que, solo por esta razón, no puede negarse un considerable carisma político. Luis Arana fue siempre un defensor radical de la fisonomía católica y ruralista del nacionalismo. El antiguo mundo de los Fueros (que había inspirado el imaginario literario y legendario de los vascos en los siglos XVIII y XIX) siempre estuvo presente en sus posiciones. Esta capacidad de representar las diferentes almas de la identidad vasca favoreció su éxito, contra las herejías representadas por los «evolucionistas» del nacionalismo, y en última instancia del mismo Sabino, el Sabino censurado por el guardián de su memoria y de su ortodoxia.

ARANZADI, Ereintza: siembra del nacionalismo vasco, San Sebastián, Auñamendi, $1980\left(1^{\mathrm{a}} \mathrm{ed}\right.$. 1935); C. DE JemeIn y LAMBARri, Biografia de Arana Goiri'tar Sabin e historia gráfica del nacionalismo, Bilbao, Editorial Geu, 1977 ( $1^{a}$ ed. 1935).

9 J.-C. Larronde, Luis Arana Goiri (1862-1951): historia del nacionalismo vasco, Bilbao, Sabino Arana Fundazioa, 2010. 